JEASP

Journal of English for Academic and Specific Purposes

Volume 2 Number 1, June, 2019

\title{
EFL LEARNERS' ABILITY IN USING DISCOURSE MARKERS TO BUILD COHERENCE IN THE WRITING
}

\author{
Ulin Ni'mah \\ (ulin147@gmail.com)
}

Pusat Pengembangan Bahasa inggris

Universitas Negeri Maulana Malik Ibrahim Malang

$\begin{array}{ll}\text { ARTICLE } & \text { ABSTRACT } \\ \text { Keywords: } & \text { The study aims to investigate how EFL learners apply Discourse Markers (DMs) } \\ \text { to make their writing coherent. This is a descriptive study conducted at UIN } \\ \text { Discourse markers, } \\ \text { Maulana Malik Ibrahim Malang by observing essays written by Biology students } \\ \text { learning English in semester IV. The researcher analyzed } 52 \text { DMs and how the } \\ \text { students apply them in } 28 \text { essays. The findings of the study show that the } \\ \text { participants use } 21 \text { different DMs in } 148 \text { occurrences, and use several DMs } \\ \text { inappropriately in } 68 \text { occurrences. There are some problems found in the use of } \\ \text { DMriting } \\ \text { Displace. The conclusion of the study reveals that learners have already applied } \\ \text { DMs in their texts to build coherence but some are used inappropriately. } \\ \text { Therefore, the researcher suggests that materials about what types of DMs and } \\ \text { how to apply DMs should be given in the classroom. }\end{array}$

\section{INTRODUCTION}

Discourse Markers (DMs) have become an interesting topic to be investigated in these recent years. Many researchers throughout the world have conducted a lot of studies about it. Carter and Fung (2007) define discourse markers as "intra-sentential and supra-sentential linguistic units that fulfill a largely non-propositional and connective function at the level of discourse. Another viewpoint of discourse markers definition is stated by Louwerse and Mitchell (in Daif-Allah and Albesher, 2013) who define discourse markers as a set of words which mark transition points in communication, facilitate the construction of a mental representation of the events described by the discourse as well as creating cohesiveness, coherence and meaning in a text. Moreover, Swan (2005) gives a more simplistic account of discourse markers as some words and expressions are used to show how discourse is constructed. They can show the connection between what a speaker is saying and what has already 
JEASP

Journal of English for Academic and Specific Purposes

Volume 2 Number 1, June, 2019

been said or what is going to be said; they can indicate what speakers think about what they are saying or what others have said.

According to Chaudron and Richards (1986), DMs can be categorized into two: macro and micro. Macro markers mean higher-order markers signaling major transitions and emphasis in a lecture. In a lecture, macro markers are essentially used to signal the transition the moves from one phase of a lecture to another phase, to indicate a shifting of one topic to another topic, and to organize the lecture structurally so that students are clear about the subject matters. Meanwhile, micro markers are considered as lower-order markers of segmentations and inter-sentential connections. They are fundamentally used as links to signal the internal or ideational relations within sentences so the relations of one clause to another clause or one sentence to another sentence are easier to comprehend.

In spoken discourse, the first and the most detailed explanation of discourse markers is that reported in Schiffrin (1987: 57-58) claiming discourse markers as sequentially dependent elements that bracket units of talk i.e. nonobligatory utterance-initial items that function in relation to ongoing talk and text. She proposed that discourse markers could be considered as a set of linguistic expressions comprised of members of word classes as varied as conjunctions (e.g. and, but, or), interjections (ob), adverbs (now, then) and lexical phrases ( $y^{\prime}$ know, I mean). Therefore, discourse markers help to integrate the many different simultaneous processes underlying the construction of discourse and thus help to create coherence. DMs are not only found in spoken discourse, in written discourse, Fraser (1990) proposes the types of discourse markers are contrastive markers, elaborative markers, inferential markers and temporal markers that connect two sentences or clauses together. The products of writing will be structurally good as they are arranged by using discourse markers. As written discourse is like spoken discourse, a communicative activity, so one of the devices that help this communicative activity to be more effective is the use of discourse markers.

Various strategies such as the communicative approach, the task-based method and the natural approach can be used to teach discourse markers to assist learners to acquire the content and improve their knowledge. In using these strategies, learners are opportune to think and use discourse markers in real-life situations. They are to classify them to carry out meaningful tasks. According to Walsh (2006), discourse markers can be used by teachers to begin a lesson and end the teaching stages. This enables the students to understand both the content and the patterns of interaction. Othman (2010) also points out that DMs assist in the establishment of interpersonal relationships during classroom discussion, providing a better environment for students ${ }^{\mathrm{ee}}$ involvement. 


\section{JEASP}

Journal of English for Academic and Specific Purposes

Volume 2 Number 1, June, 2019

Writing is a prominent skill to be learned by students since they are required to write some English works in teaching and learning process. In fact, writing is not an easy skill; many students still face some problems to write a passage. That English is a foreign language, which has different structure rules and difficult vocabularies, makes students need more effort to get writing skill. In addition, one of the reasons why writing skill is hard to get is because it is the product of thinking process. Brown (2000) states that written products are often the result of thinking, drafting, and revising procedures that require specialized skills, skills that not every speaker develops naturally. The upshot of the compositional nature of writing has produced writing pedagogy that focuses students on how to generate ideas, how to organize them coherently, how to use discourse markers and rhetorical conventions to put them cohesively into a written text, how to revise text for clearer meaning, how to edit text for appropriate grammar, and how to produce a final project.

The students to make their writing more cohesive can use discourse markers. Their ideas can be arranged in a good order by using them so the readers will understand the message delivered by the writer. The use of discourse markers can help students to connect sentences and paragraphs effectively, show logical order between the previous ideas and the following ones and help the readers interpret the passage easily. Swan (2005) asserts that the use of discourse markers also enables speakers or writers make the context more accessible to listeners or readers and constrain their interpretation of message through using discourse markers in communication. Blakemore (2002) points out that the readers' understanding of utterances is a consequence of the organization of discourse, it is then clear that it is worth looking at the organization of discourse in order to discover what this organization consists in.

McCarty (1993:153-155) also supports the role of discourse markers that can influence the writing quality. It is possible to devise interactive activities that involve decisions on word order, cohesion and sequences of tenses in discourse. The inappropriate use of conjunctions creates difficulties for the reader in relating segments of the text to one another coherently. Therefore, conjunction and other local cohesive choices as part of discourse markers may also be useful to construct well-formed written discourse that can be comprehended by the readers. Furthermore, he explains that coherence is the feeling that a text hangs together, that it makes sense and it is not just a jumble of sentences so, cohesive markers are no exception: they create links across sentences boundaries and pair and chain together items that are related (e.g. by referring to the same entity). 


\section{JEASP}

Journal of English for Academic and Specific Purposes

Volume 2 Number 1, June, 2019

In accordance with the correlation between the use of DMs (Discourse Markers) and writing achievement, some researchers have conducted some research related to the correlation between them. Daif-Allah and Albaser (2013) studied the use of Discourse Markers at Qassim University. They examined a hundred paragraphs that were analyzed qualitatively and quantitatively to find what DMs that are frequently used and the correlation between the frequency of using DMs and test scores. Finally, they found additive, contrastive, illustrative and causal as DMs that were mostly used and there was statistically significant correlation between the paragraphs score and the number of DMs of each category presented in the same paragraph. The problems of DMs use such as misuse, overuse, and underuse were found in the students' writing (Cho, 1998; Bolton, Nelson \& Hung, 2002).

Based on the previous studies focusing on the discourse markers used by students and the students' writing achievement, so the researcher considers to investigate the students' ability in using discourse markers.

\section{METHOD}

This is a descriptive research conducted at UIN Maulana Malik Ibrahim Malang. The participants are Biology students studying English II that focuses on Writing and Speaking from the fourth semester class in 2017-2018. The researcher analyzed argumentative essays that have been assigned by the researcher as the lecturer in the learning process. There were 28 essays assessed by the researcher. The DMs investigated in this study are 52 DMs adapted from Fraser's (1999) and Halliday and Hasan's (1976) taxonomy.

Table 1 Taxonomy of DMs Adapted from Fraser's (1999) and Halliday and Hasan's (1976)

\begin{tabular}{ll}
\hline Elaborative Markers & \\
\hline Additive Markers & $\begin{array}{l}\text { And, in addition, further, besides, additionally, } \\
\text { moreover, furthermore, similarly, likewise }\end{array}$ \\
Appositive Markers & Otherwise, in other words, that is, in one word \\
Illustration Markers & For example, for instance \\
Summative Markers & In short, in sum, in brief, in summary, in \\
& conclusion, to sum up
\end{tabular}




\section{Adversative Markers}

Concessive Markers

Corroborative Markers

Corrective Markers

Contrastive Markers

\section{Causal-Inferential Markers}

But, however, nevertheless, nonetheless, yet, still, though

In fact, indeed, of course

Instead, on the contrary, rather

On the other hand, in contrast, by contrast, conversely, alternatively

Thus, so, therefore, (in) this way, then, hence, in this respect, in this case, consequently, as a result, as a consequences, for this reason, accordingly.

This study includes some steps. The first step is extracting every word and expression of DMs with their adjacent sentences, the extracted DMs are coded, categorized, and analyzed to identify if they are applied properly. To ensure the credibility and validity of the findings, the researcher involves a triangulation procedure by assigning a rater who has Master's degree in TEFL to assist the researcher observe the use of DMs. Moreover, there is also participants' verification to verify and confirm the researcher's interpretation as to why the participants apply such DMs in their essay.

\section{FINDINGS AND DISCUSSION}

\section{DMs used by EFL Students}

The findings show that the participants use 21 different DMs in 148 occurrences, and 68 DMs are applied inappropriately. 73 of which are used in the beginning of the sentences, and are always followed by a comma. This reveals that they seem to break a complex sentence into a simple one and add a DM at the beginning of the second segment to show a topic change. The DMs usage supports McCarthy's (1993) claim that a DM can constitute and extend the content of discourse better than a conjunction.

Based on DMs taxonomy by Fraser (1999) and Halliday and Hasan (1976), the research findings reveal that there are 148 occurrences of using DMs in the students' argumentative essay. The number of DMs occurrences is described in Table 2.

Table 2 depicts that there is high number of both adversative and causal inferential markers. It is possibly caused by the nature of the argument text. Causal-inferential markers show the highest frequency of occurrence for the participants to deliver the causes of certain issues. They give the 
JEASP

Journal of English for Academic and Specific Purposes

Volume 2 Number 1, June, 2019

evidence for argumentative claims to support their opinion so the readers agree with them. The presence of the adversative markers is mostly used to demonstrate some cases and to anticipate the opposite ideas from the readers' views and refute them. Besides, they apply the adversative markers to elaborate their ideas by giving additional information and describing examples.

Table 2 The DMs Category in the Students' Essays

\begin{tabular}{lc}
\hline Types & Occurrences \\
\hline Causal-inferential Markers & 57 \\
Adversative Markers & 48 \\
Elaborative Markers & 43 \\
\hline
\end{tabular}

\section{Problems Encountered by the Participants in Using DMs}

The researcher finds several problems in the use of DMs written in the participants' argumentative essays. The problems are categorized into: mistranslation, overuses, misinterpreted relation, and misplace. Based on the finding, the students with good writing ability tend to apply various kinds of DMs to make their essays more sophisticated and avoid using the same DMs since repetition in a written essay decreases its value. In fact, despite good students use wider range of DMs compared to those who are not, the researcher still notices some problems. On the other hand, participants with a lower proficiency tend to apply a few DMs which is probably caused by the lack of DMs knowledge and familiarity. As the result, their essays show many repetitions of DMs and inappropriate use of DMs.

\section{Mistranslation Problems}

Mistranslation is a case of transferring L1 to their L2 sentences without considering the appropriateness and accuracy in L1 grammar rules. It possibly occurs since the participants have poor knowledge in using some markers in a text. The sample of mistranslation problem is described below.

1) In my opinion it definitely falls to the parents to make sure that their children get the best start in life possible and that they do all they can in terms of leading by example, instilling values and behavioural standards which will equip their children for life. The 
JEASP

Journal of English for Academic and Specific Purposes

Volume 2 Number 1, June, 2019

school system has its part to play, without doubt, but it should be a secondary role to that of parents.

In example 1, after showing an opinion of parents giving the best education for their children, the subject applies DM by example as an illustration marker, which is Indonesian-English word-by-word translation for 'sebagai contoh'. The intended meaning is for example, but because of the poor knowledge and practice, the subject easily translates by example instead of for example. This subject's problem supports the previous findings investigating about the relationship between L1 and culture (Biber \& Finegan, 1988; Altenberg \& Tapper, 1988; Mauranen, 1993).

\section{Overuse Problems}

Overuse is the most common problem found in the participants' essays. The problems happen when the relation between sentences is so obvious that it does not need any DMs, as seen in the example below.

2) So $i$ want them to confidence to their self to shout out something. But the biggest role model for children is us their parents. But society determined too. I want my children also learn everything not only from school but from the around. If its bad leave it but if it good take it. I want them to be a good listener tho. Appresiate others oppinion and else. Yahh it depend on how we or us our future parents mother and father teach them.

As shown in the example there is three sentences in one paragraph, which begin with a DM. This problem could be caused by misconception about the use of DMs in composing a text, which is assumed to be better. The DM but and but are used twice when both can be applied in one sentence to show two reasons of role model. In fact, the writer can only use one DM but in the sentence.

As observed in the data analysis, there are two reasons causing the overuse problems happen in the participants' compositions. First, the students might think that the more DMs they use, the better their essays, which are a misconception of the DMs, use. Second, the participants' perception about the readers, they possibly underestimate the readers' knowledge; or, assume that the readers can understand their essays by using another DMs. Therefore, the writers believe that they must link the sentences using more than one DMs.

This study found the same research finding done by Mumbi \& Simwinga (2018) that showed that participants of their investigation experience a multiplicity of challenges in the use of DMs, one of 
which is overuse problems. The problem causes the essay incoherent and difficult to understand by the readers.

\section{Surface Logic Problems}

Surface logic is about the problem that students try to impose logic to the passage, or to link the gap among propositions where there is no relation between sentences. The sentences below are the example of the problem.

3) Moral education can be given to children through learnings in schools. This education can be added through subjects such as counseling. And will be a good and effective if moral education is also provided in the family. So every family, especially the parents, can provide moral education lessons to their children. A good example in living a full life with a positive attitude and morals, very influential for children. The children would imitate their parents activities. So when parents do a good thing, a little more children will also follow them. As the saying goes "Mother is the first school for their children". Therefore, for the parents, teach your children for the better future generations.

According to the data above, the writer use four DMs to begin every sentence in one paragraph. The DM so is repeated twice and therefore has also the same meaning as the causal-inferential markers. The use of two types of DM does not make the sentences logical. The participants probably opine that their argumentative texts are written for and to their lecturer to read and assess, so they use more DMs to make them more coherent and achieve good score. They do not consider if many DMs used in one paragraph will make the essays incoherent and poor in quality.

\section{Misinterpreted Relation Problems}

Misinterpreted relation is a problem about the relation linked by the DMs does not correspond to the relation that exists between sentences. In this case, the participants do not seem to understand what DMs should be applied to connect two sentences so the relation is coherent. Excerpt from the subject's writing below may illustrate the problem.

4) While the parents are the people who first take care of us and raise us. Parents choose to send their children to school or not for a variety reasons. One of them maybe they have home tutoring where mum, dad or a tutor works with them in their own home. But the school is very important for their child because many parents are busy with their work so 


\section{JEASP}

Journal of English for Academic and Specific Purposes

Volume 2 Number 1, June, 2019

they prefer to send their children to school so their children still get attention, love, and knowledge from their teacher and friends.

The beginning sentences of the paragraph describe the definition of parents and their roles in providing education for their children. The next sentence starting with DM but gives information about the fact that school is an important institution to support children's education. In this case, the subject does not use appropriate DM to link the sentences, in fact as a corroborative marker should be applied instead of but.

This finding supports the research conducted by Adeyemi (2018) analyzing discourse markers used by students at Ondo State University of Science and Technology. It showed that 141(53.2\%) of the respondents had low understanding of discourse markers such as: in addition, followed by linkers showing relationship with 137(51.2\%). The results further showed that

$231(87.2 \%)$, representing majority of the respondents were of the view that lack of mastery of the various connectors is a major barrier to effective writing. Thus, many students still find difficulties in using DMs in their writing.

\section{Misplace Problems}

Misplace problems happen when the writers do not how to write DMs within a sentence. They do not have any idea that Some DMs should be used in the beginning or in the middle while others should not be used. The following sample shows the misplace problem.

5) But unlike us, for example we have a talent in the field of music or theater. If we are noble and have the support of parents will get results that will eventually lead us into success.

As can be seen in the example, DM but as concessive marker should be used in the middle of sentence to connect two sentences in the formal discourse however the writer applies but in the beginning of the sentence. They might do not know the different use of DMs in formal and informal discourses. In the novel or poem, it is possible to use DM but in the beginning of the sentence but it is not in formal essays. Many students make mistakes in writing the DMs such as but and and in the beginning of their sentences.

The results of this study support the research findings by Wuwuh (2014) who revealed that there were several problems in the use of DMs (misplace problem, use of DMs in complex sentences, 


\section{JEASP}

Journal of English for Academic and Specific Purposes

Volume 2 Number 1, June, 2019

overuse of the DMs, and repetition of the use of DMs) and were encountered differently by both groups of students (Indonesian and Thailand). This study also revealed that there was a relationship between the use of the DMs and text coherence that supports the previous study.

\section{CONCLUSION AND SUGGESTION}

In summary, the findings show the students' ability in using DMs in their writing by showing the number of DMs applied, however there are some problems found by the researcher such as mistranslation, overuse, surface logic, misinterpretation, and misplace. The problems occur due to several reasons, which might be the lack of knowledge and practice in using DMs. Therefore, it is necessary for the lecturers to give the material about what kinds of DMs and how to use DMs in composing a text. The lecturers should also explain that DMs should be used to connect sentences since they make a text more coherent.

\section{REFERENCES}

Adeyemi, B. (2018). Use of Discourse Markers in Writing and Answering Essay Questions among Undergraduates in Ondo State University of Science and Technology, Okitipupa, Nigeria. International Journal of Learning, Teaching and Educational Research, 17(7), 106-119.

Altenberg, B., \& Tapper, M. (1998). The Use of Adverbial Connectors in Advanced Swedich Learners' Written English. In S. Granger (Ed.), Learner English on Computer (pp. 80-93). New York: Longman.

Biber, D., \& Finegan, E. 1998. Adverbial Stance Types in Englosh. Discourse Processes, 11(1), 1-34.

Blakemore, D. (2002). Relevance and Linguistic Meaning. The Semantics and Pragmatics of Discourse Markers. Cambridge: Cambridge University Press.

Bolton, K., Nelson, G., \& Hung, J. (2002). A Corpus-based Study of Connectors in Student Writing. Research from the International Corpus of English in Hong Kong (ICE-HK). International Journal of Corpus Linguistics, 7(2), 165-182.

Brown, H.D. (2000). Teaching by Principles. An Interactive Approach to Language Pedagogy. $2^{\text {nd }}$ Edition. London: Longman.

Carter, R \& Fung, L. (2007). Discourse Markers and Spoken English: Native and Learner Use in Pedagogic Settings. Applied Linguistics, 28, 410-439. 


\section{JEASP}

Journal of English for Academic and Specific Purposes

Volume 2 Number 1, June, 2019

Cho, Y. (1998). Use of Connectives in Writings by Korean Learners of English. (Report No. ED441348).

Chaudron, C \& Richards, J. C. (1986). The Effect of Discourse Markers on the Comprehension of Lectures. Applied Linguistics, 7(2), 113-127.

Daifallah, D.A \& Albesher, K. (2013). The Use of Discourse Markers in Paragraph Writings: The Case of Preparatory Year Program Students in Qasim University. Canadian Center of Science and Education, 6(9).

Fraser, B. (1990). An Approach to Discourse Markers. Journal of Pragmatics, 14, 383-95.

Fraser, B. (1999). What Are Discourse Markers? Journal of Pragmatics, 31(7), 931-952.

McCarthy, M. (1993). Discourse Analysis for Language Teachers. Cambridge: Cambridge University Press.

Mumbi, Cm,M \& Simwinga, J. (2018). Challenges in the Use of Discourse Markers in English as Second Language (ESL) Writing: Evidence from Selected Grade Twelve Pupils in Kitwe District, Zambia. International Journal of Humanities and Cultural Studies, 5(2), 214-234.

Halliday, M.A.K. \& Hasan, R. (1976). Cohesion in English. London: Longman.

Othman, Z. (2010). The use of okay, right and yeah in academic lectures by native speaker lectures. Discourse Studies, 12(5), 665-681.

Schiffrin, D. (1987). Discourse Markers. Cambridge: Cambridge University Press.

Swan, M. (2005). Practical English Usage. Oxford: Oxford University Press.

Walsh, S. (2006). Investigating classroom discourse. New York: Routledge.

Wuwuh, A. (2014). The use of English discourse markers in the argumentative writing of EFL Indonesian and Thai University students: A comparative study. Journal of Education, 7(1), 3339. 